\title{
Can orthographic rimes facilitate naming?
}

\author{
MARIE MONTANT \\ Université de Provence, Marseille, France \\ and Carnegie Mellon University, Pittsburgh, Pennsylvania \\ and \\ JOHANNES C. ZIEGLER \\ CNRS and Université de Provence, Marseille, France \\ and Macquarie Centre for Cognitive Science, Sydney, Australia
}

\begin{abstract}
Although the orthographic rime (body) is thought to play an important role in reading English, previous priming experiments found little or no evidence for facilitatory body-priming effects in the naming task. That is, hose primes NOSE no better than does a completely unrelated prime. In the present study, the hypothesis that facilitatory body-priming effects are typically masked by strong inhibitory onset effects was investigated. It was shown that when the onset of a prime was removed, facilitatory body priming could be obtained with stimuli that previously had produced no evidence of facilitation. The present study thus reconciles conflicting patterns concerning facilitation versus inhibition in body priming.
\end{abstract}

A large body of evidence shows that rimes function as units in speech perception, speech production, and verbal working memory (see Treiman, 1989). Similarly, rimes seem to play an important role in learning to read, possibly because of the availability of the rime as a phonological structure early in childhood (e.g., Bowey \& Hansen, 1994; Treiman, Goswami, \& Bruck, 1990; Treiman, Mullennix, Bijeljac-Babic, \& Richmond-Welty, 1995). Given these findings, one might expect that the orthographic equivalent of the rime, the body, may also function as a unit in visual word recognition in adults. In fact, a number of studies on skilled reading have supported this prediction (e.g., Bowey, 1990, 1993, 1996; Brown, 1987; Brown \& Watson, 1994; Forster \& Taft, 1994; Rosson, 1985; Taft, 1992; Ziegler \& Perry, 1998). Most important, it has been shown that words or nonwords constructed from relatively common bodies were read faster and more accurately than those constructed from less common bodies (e.g., Brown \& Watson, 1994; Rosson, 1985; Treiman et al., 1990).

Such positive demonstrations of a facilitatory role of the body stand in sharp contrast to the absence of facilitatory body effects in primed naming. For example, Lukatela and Turvey (1996) showed that naming was not facilitated but inhibited when a target word was preceded by a body prime (e.g., nose-HOSE). Similarly, Lupker and Colombo (1994) found virtually no evidence of facilitation for body priming, except when the target was a lowfrequency irregular word (e.g., wash-SQUASH). Finally,

This research was supported by a DGA grant to M.M. We thank Marlene Behrmann for helpful comments on a previous version of the manuscript. Correspondence concerning this article should be addressed to M. Montant, Laboratoire de Psychologie Cognitive, Université de Provence, Centre St. Charles, case 66, 3, place Victor Hugo, 13331 Marseille cedex 3, France (e-mail: montant@up.univ-mrs.fr).
Pexman, Christi, and Lupker (1999) showed that whereas enemy primes (e.g., word-CORD) generally inhibited naming, ${ }^{1}$ friend primes (e.g., need-WEED) never facilitated naming, unless the primes were named aloud.

The absence of facilitatory body effects in primed naming is puzzling for a number of reasons. First, it seems incompatible with the finding that words with common bodies are read faster and more accurately than words with less common bodies (e.g., Brown \& Watson, 1994; Rosson, 1985; Treiman et al., 1990). If bodies facilitate naming in an unprimed situation, why can they not facilitate naming in a priming situation? Second, if bodies are important psycholinguistic units in children, they should remain important in adults, especially given that body usage seems positively correlated with reading proficiency (Bowey \& Underwood, 1996). Third, given Treiman et al.'s (1995) demonstrations that the body, as a statistical unit, can help to disambiguate the inconsistent vowel pronunciation in English, there is no reason to expect anything else but facilitation to come from the body.

In the present article, we investigate why body effects, although present in various unprimed situations, seem to be hard to obtain in primed naming. In fact, a closer look at the only studies that found body effects in primed naming (Bowey, 1990, 1993) points to an interesting methodological detail. Bowey $(1990,1993)$ obtained facilitatory body priming, but her primes consisted of the body only (e.g., ait-BAIT). In contrast, other body-priming studies typically primed with a whole word, including the onset (e.g., hose-NOSE). Is it possible that this seemingly irrelevant methodological detail could be responsible for the presence or absence of body effects in naming?

A first answer to this question comes from a study by Grainger and Ferrand (1996). These authors were confronted with explaining a similar null effect—namely, why 
pseudohomophones like brane were no better primes for naming BRAIN than were nonpseudohomophones like brate. Their hypothesis was that facilitation from shared onsets was so strong that having more than the onset in common did not facilitate over and above having just the onset in common. To prove their hypothesis, they showed that primes that shared just the onset (broll-BRAIN) were as efficient as primes that shared more than the onset (brane-BRAIN). Similarly, they showed that when the onset was replaced with a percent sign, pseudohomophones like brane (\%ane-BRAIN) became better primes than nonpseudohomophones like brate (\%ate-BRAIN).

A second answer to this question comes from experiments by Forster and Davis (1991). Whereas Grainger and Ferrand (1996) showed that shared onsets can facilitate primed naming, Forster and Davis showed that different onsets can inhibit primed naming. This so-called onset effect is a Stroop-like inhibitory effect that shows up when primes and targets begin with different onsets. Because words that rhyme (e.g., hose-NOSE) have, by definition, different onsets, it is conceivable that a facilitatory body effect could be cancelled out by a strong inhibitory onset effect. Thus, taking the results of these two studies together, one could predict that facilitatory body effects should reemerge for stimuli that previously produced no evidence of facilitation when the inhibitory onset of a prime was removed or replaced by a percent sign.

This hypothesis was tested using the stimuli of the most comprehensive study on body effects in primed naming that failed to find facilitatory effects for body primes (i.e., Pexman et al., 1999). These authors used a primed naming procedure with three stimulus onset asynchronies (SOAs) $(129,314$, and $814 \mathrm{msec})$. The primes were either high or low in frequency, and they were either regular or irregular. Regular primes contained the same orthographic and phonological body as the target; they were socalled friends (e.g., need-WEED). Irregular primes contained the same orthographic body as the target, but their pronunciation differed; they were so-called enemies (e.g., word-CORD).

In order to test our hypothesis, we replaced the onset of the prime by a percent sign for one group of subjects. For the other group of subjects, the onset of the prime was present. If the onset hypothesis was correct, we should obtain facilitation for Pexman et al.'s (1999) stimuli when the onset of the primes was taken off. Conversely, the same stimuli should produce either no effect or an inhibitory effect when the prime onset was intact. With respect to prime regularity, in the with-onset condition, it was predicted that irregular primes (word-CORD) should produce more inhibition than regular primes (need-WEED). In the without-onset condition, no effect of prime regularity was expected, because irregular bodies without onsets (e.g., ord) are likely to become regularized.

Finally, because we were interested in investigating at what point facilitation or inhibition emerged and how it developed over time, we used four SOAs $(50,66,83$, and
$100 \mathrm{msec}$ ), starting with a short SOA at which primes should not be visible (e.g., Forster, Davis, Schoknecht, \& Carter, 1987). The same subjects were used across all SOAs in order to have a within-subjects baseline against which the effects of facilitation and inhibition could be assessed $^{2}$ (e.g., Grainger \& Jacobs, 1999; Jacobs, Grainger, \& Ferrand, 1995; Ziegler, Ferrand, Jacobs, Rey, \& Grainger, 2000).

\section{METHOD}

\section{Subjects}

Sixteen undergraduate students at Carnegie Mellon University participated in the study. Eight of them were tested in the with-onset condition, and 8 were tested in the without-onset condition. The subjects received course credit for their participation. All the subjects were native English speakers and had normal or corrected-tonormal vision.

\section{Stimuli}

The stimuli were taken from Pexman et al. (1999, Experiments 1 and 2). They consisted of 128 monosyllabic prime-target word pairs, of which 64 were related and 64 unrelated pairs. In the related condition, 32 primes were regular, and 32 were irregular. Regular primes contained a body that was orthographically and phonologically identical to the body of the target - the prime and the target were friends (e.g., need-WEED). Irregular primes had the same orthographic body as the target but a different pronunciation- the prime and the target were enemies (e.g., word-CORD). In both the regular and the irregular priming conditions, half of the primes (16) were low-frequency words, and half were high-frequency words (below or above 55-60 occurrences per million, respectively; Kučera \& Francis, 1967). All the targets were low-frequency regular words. In the unrelated priming condition, the same 64 targets as those described for the related condition were used, but paired with orthographically and phonologically dissimilar primes (e.g., whatCORD). In the without-onset condition, the stimuli were identical to the ones described above, except that the onset of each prime (in all the conditions) was replaced by a percent sign (e.g., \%eed-WEED, \%ord-CORD).

\section{Procedure}

The stimuli were presented on the screen of a 540C Macintosh PowerBook computer controlled by PsyScope (Cohen, MacWhinney, Flatt, \& Provost, 1993). The stimuli were displayed in an 18-point Courier font, in lowercase letters for the primes and in uppercase letters for the targets. A voice key interfaced with PsyScope was used to measure vocal reaction times (RTs).

On each trial, the subject was presented with a sequence of four stimuli: a premask for $500 \mathrm{msec}$, the prime for $17,33,50$, or $67 \mathrm{msec}$, a postmask for $33 \mathrm{msec}$, and the target for an unlimited duration. The masks consisted of a string of six hash marks (\#). The four stimuli followed each other with an interstimulus interval of $0 \mathrm{msec}$. Accordingly, the SOA was 50,66, 83, or $100 \mathrm{msec}$, depending on the duration of the prime. The subjects were asked to read the target aloud as rapidly and as accurately as possible. Each trial was triggered by the experimenter. Naming was considered erroneous when the target word was mispronounced or when the subject's pronunciation was hesitant. Responses that did not trigger the voice key were not considered as errors and were removed from the data. The 128 prime-target pairs were presented four times to each subject, once for each prime duration. The stimuli were blocked per prime duration. For each subject and each block, the order of the stimuli was randomized. The order of the blocks was balanced across sub- 
jects and was identical in the with-onset and the without-onset conditions. There was a short break between two consecutive blocks.

\section{RESULTS}

The overall results averaged across prime durations are presented in Table 1 . Because the error rates were fairly low and evenly distributed across conditions $(1.23 \%$ and $1.24 \%$ for with-onset and without-onset, respectively), they are not further considered for statistical analysis. RTs that were three standard deviations beyond the individual grand mean were excluded. This trimming procedure excluded 32 scores ( $0.3 \%$ of the data). Furthermore, 119 scores were excluded because of voice key errors (1.45\% of the data). In the subject analysis $\left(F_{1}\right)$, the RT data were submitted to a five-way factorial analysis of variance (ANOVA), with onset type (with vs. without) as a between-subjects factor and relatedness (related vs. unrelated), SOA (50, 67, 83, and $100 \mathrm{msec}$ ), prime regularity (regular vs. irregular), and prime frequency (high vs. low) as within-subjects factors. In the item analysis $\left(F_{2}\right)$, onset type, relatedness, and SOA were treated as within-items factors, and regularity and frequency were between-items factors.

As can be seen in Table 1, the overall priming pattern in terms of facilitation and inhibition differed for the same targets as a function of whether or not the prime's onset was present. In the first case (with onset), no reliable facilitation was obtained in any of the prime conditions. Inhibition was obtained for high-frequency irregular primes. In the second case (without onset), both regular and irregular primes produced reliable facilitation (for statistical analyses, see below).

The ANOVAs showed that the main effect of relatedness was significant by subjects and items $\left[F_{1}(1,14)=9.5\right.$, $\left.p<.005 ; F_{2}(1,60)=14.9, p<.001\right]$. The main effects of onset type and SOA were significant only by items [onset type, $F_{1}(1,14)=0.28, p>.50$, and $F_{2}(1,60)=78.5$, $p<.001$; SOA, $F_{1}(3,42)=1.5, p>.10$, and $F_{2}(3,180)=$ $39.6, p<.001]$. More important, there was a significant interaction between the effects of relatedness and onset type $\left[F_{1}(1,14)=16.1, p<.005 ; F_{2}(1,60)=30.5, p<\right.$ $.0001]$, confirming that the overall priming pattern dif- fered depending on whether the onset was present or replaced by a percent sign.

This dissociation was further specified by a triple interaction between the effects of relatedness, onset type, and SOA $\left[F_{1}(3,42)=2.5, p<.08 ; F_{2}(3,180)=4.1, p<\right.$ $.01]$. This triple interaction is illustrated in Figure 1. This figure clearly shows that, when the onset is present, no priming is obtained for the first three SOAs. A significant priming effect was obtained only for the longest SOA $\left[F_{1}(1,21)=6.1, p<.05 ; F_{2}(1,180)=7.2, p<\right.$ $.005]$. However, this priming effect was inhibitory in nature, with related primes producing longer latencies than did unrelated primes ( $547 \mathrm{vs} .537 \mathrm{msec}$ ). When the onset of the prime was replaced by a percent sign, significant facilitatory priming effects were obtained at all SOAs (all $F \mathrm{~s}>4.3, p \mathrm{~s}<.05$ ). None of the other interactions involving the effects of onset type, relatedness, or SOA approached significance.

As concerns the effects of prime regularity and prime frequency, none of the main effects reached significance (all $p s>.10$ ). Similarly, except for one, none of the interactions involving prime regularity and prime frequency was significant. Only the second-order interaction between prime frequency and prime regularity was significant by subjects, but not by items $\left[F_{1}(1,14)=10.8, p<.01\right.$; $\left.F_{2}(1,60)=1.7, p<.20\right]$. This interaction must reflect absolute RT differences between the four groups of items. Because these differences occurred regardless of whether the primes were related or unrelated (i.e., the critical triple interaction with relatedness was not significant; all $p \mathrm{~s}>$ .30 ), the present second-order interaction is theoretically not very interesting.

The net priming effects given in Table 1 were further assessed in separate ANOVAs for each onset condition (withonset and without-onset). In the with-onset condition, the analyses showed that only irregular high-frequency primes produced an inhibitory priming effect that was significant by items, but not by subjects $\left[F_{1}(1,7)=1.4, p>.25\right.$; $\left.F_{2}(1,15)=16.1, p<.001\right]$. All other prime types showed no significant priming effects (all $F \mathrm{~s}<1$ ). In the withoutonset condition, significant facilitation was obtained for all the prime types [high frequency regular, $F_{1}(1,7)=16.3$, $p<.01$, and $F_{2}(1,15)=15.46, p<.005 ;$ high-frequency

Table 1

Mean Latencies (RTs, in Milliseconds), Percentage of Errors (PEs), and Net Priming Effects (Unrelated Minus Related) for All Priming Conditions Averaged Across the Four Stimulus Onset Asynchronies

\begin{tabular}{|c|c|c|c|c|c|c|c|c|c|c|}
\hline \multirow[b]{3}{*}{ Prime Type } & \multicolumn{5}{|c|}{ With Onset } & \multicolumn{5}{|c|}{ Without Onset } \\
\hline & \multicolumn{2}{|c|}{ Related } & \multicolumn{2}{|c|}{ Unrelated } & \multirow[b]{2}{*}{ Net Priming } & \multicolumn{2}{|c|}{ Related } & \multicolumn{2}{|c|}{ Unrelated } & \multirow[b]{2}{*}{ Net Priming } \\
\hline & RT & $\mathrm{PE}$ & RT & $\mathrm{PE}$ & & RT & $\mathrm{PE}$ & RT & $\mathrm{PE}$ & \\
\hline \multicolumn{11}{|l|}{ High frequency } \\
\hline Regular & 540 & 1.0 & 537 & 0.5 & -3 & 513 & 1.9 & 526 & 1.7 & $+13 \dagger$ \\
\hline Irregular & 530 & 1.6 & 521 & 1.5 & $-9 *$ & 511 & 1.5 & 519 & 1.1 & $+8 \dagger$ \\
\hline \multicolumn{11}{|l|}{ Low frequency } \\
\hline Regular & 528 & 1.0 & 529 & 1.2 & +1 & 505 & 0.2 & 519 & 0.4 & $+14 \dagger$ \\
\hline Irregular & 533 & 1.7 & 534 & 1.2 & +1 & 512 & 1.5 & 525 & 1.7 & $+13 \dagger$ \\
\hline
\end{tabular}



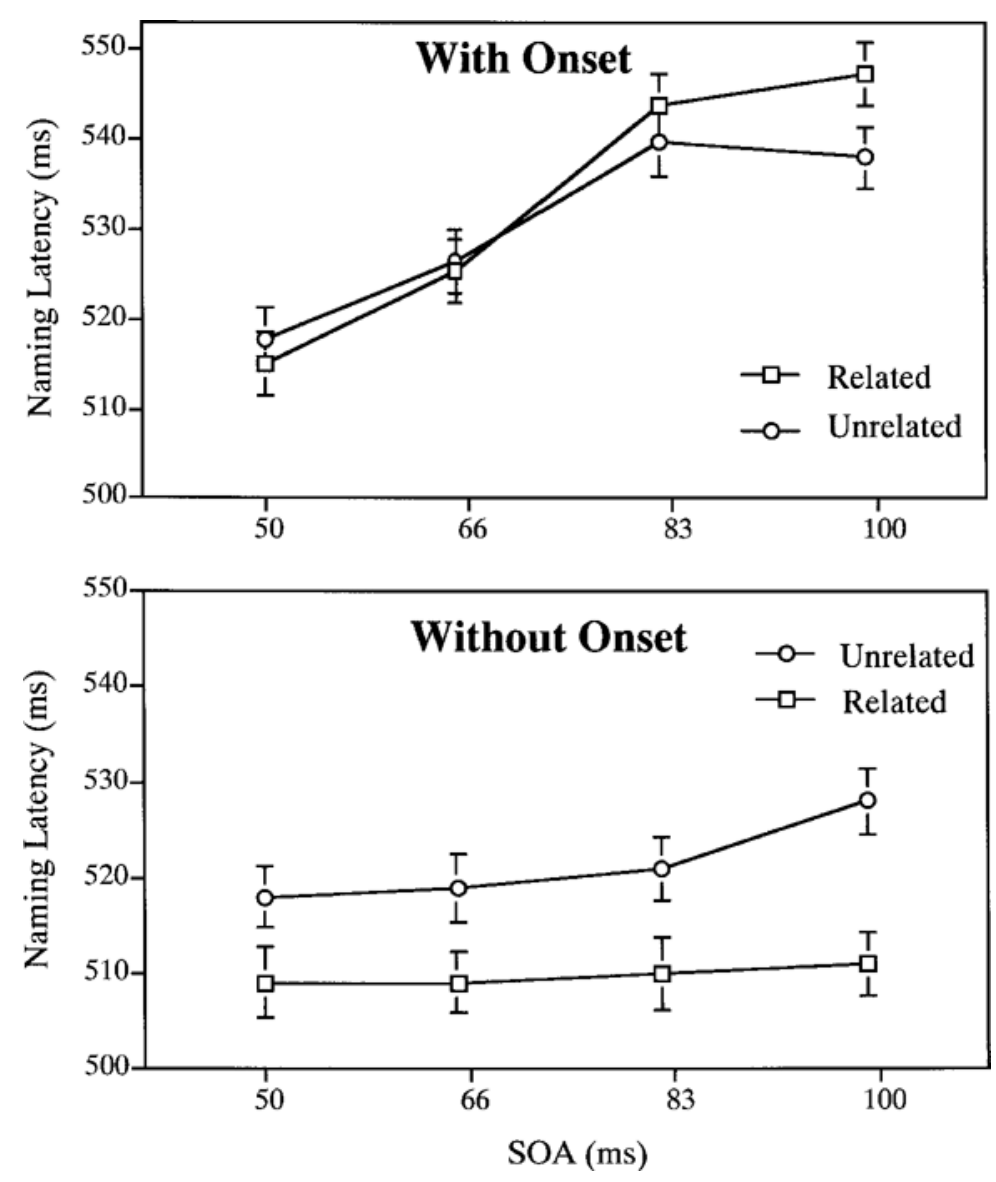

Figure 1. Body-priming effects as a function of stimulus onset asynchrony (SOA) for the with-onset group (hose-NOSE) and the without-onset group (\%ose-NOSE).

irregular, $F_{1}(1,7)=10.3, p<.05$, and $F_{2}(1,15)=5.02$, $p<.05$; low-frequency regular, $F_{1}(1,7)=21.1, p<.01$, and $F_{2}(1,15)=15.29, p<.005$; low-frequency irregular, $F_{1}(1,7)=15.6, p<.01$, and $\left.F_{2}(1,15)=7.53, p<.05\right]$.

\section{DISCUSSION}

The present study addressed the question of whether body priming in naming can be facilitatory. This would be expected if the body played an important role in skilled reading (e.g., Treiman et al., 1995). Previous research seemed to find little or no evidence for a facilitatory bodypriming effect in naming (e.g., Lukatela \& Turvey, 1996; Lupker \& Colombo, 1994; Peter, Lukatela, \& Turvey, 1990; Pexman et al., 1999). Given that the only studies that found facilitatory effects used primes without onsets (Bowey, 1990, 1993), it was hypothesized that facilitatory body-priming effects may be masked by strong inhibitory onset effects (Forster \& Davis, 1991).

The results clearly confirmed this prediction. When the onset of primes was present, no facilitation was obtained. Instead, inhibition occurred for high-frequency irregular primes (word-CORD). This pattern perfectly replicates Pexman et al.'s (1999) results, which showed that body primes produced no facilitation but did produce inhibition for high-frequency irregular primes at short SOAs. However, when a prime's onset was removed, robust facilitatory body priming was obtained at all SOAs, replicating the results of Bowey $(1990,1993)$. It thus seems that conflicting onsets (nose-HOSE) produce such massive inhibition in naming that facilitatory body priming can be detected only when this source of inhibition is eliminated.

Although this explanation seems appealing at first glance, a more detailed explanation is needed to explain how different onsets can mask potential body effects, especially because both related and unrelated primes differed from targets in terms of onset. Thus, if there were onset inhibition, it should have been equivalent in the related and the unrelated conditions, allowing any effects of body priming to show up. However, if we take into account that articulation proceeds from left to right, one can easily see how mismatching onsets can erase body effects. Assume that the presentation of the prime activates a specific onset and body in a phonological output buffer. When it comes time to generate the pronunciation of the target, the information already in the buffer can be used in the case of a match between a prime and a target (i.e., there would be savings in the conversion from a phono- 
logical code to an articulatory code). In the case of a mismatch, however, everything in the buffer would have to be discarded. Now, given that articulation is strictly from left to right, even if the rime of the target has been calculated in advance, this information would have to be discarded if different onsets were involved. In favor of this interpretation, Meyer (1990) showed, in an implicitpriming paradigm, that knowing the first syllable when producing a two-syllable word facilitated naming. However, knowing the second syllable if the first syllable was unknown did not facilitate naming. This was also the case for onsets and rimes: Knowing the rime of a word to be named in advance was of no help if the subject did not know what the onset was (Meyer, 1991). Thus, as far as articulation is concerned, the onset is of primary importance. These data offer a plausible explanation for how onset mismatch can preclude body facilitation, without having to rely on the idea that the system is simply swamped by strong onset inhibition ${ }^{3}$ (see Kinoshita, 2000, for more data on the effect of onset priming in the planning of articulation).

As is illustrated in Figure 1, there is an additional hint in the present data in support of the claim that different onsets indeed produce strong interference in naming. In the with-onset condition, overall latencies increased quite dramatically with increasing prime duration, suggesting that target processing became progressively inhibited with increasing prime availability (see also note 2 ). If an onset mismatch was responsible for this global inhibition, we would expect that both the related and the unrelated primes would produce almost identical inhibitory patterns, because both have different onsets relative to the target word. This was the case. In contrast to the systematically increasing inhibition obtained in the with-onset condition, in the without-onset condition overall latencies increased much less with increasing prime availability, presumably because neither the related nor the unrelated primes had conflicting onsets with respect to the targets.

Our data show not only that different onsets can produce inhibition, but also that body priming can be inhibitory. As in Pexman et al.'s (1999) study, high-frequency irregular primes (enemies) in the with-onset condition were found to inhibit naming of the regular targets (e.g., word-CORD). As a matter of fact, if we were to plot our data (which ended at an SOA of $100 \mathrm{msec}$ ) next to Pexman et al.'s data (which started at an SOA of $128 \mathrm{msec}$ ), one would see a perfect continuity in the pattern of inhibition across the two studies. An apparent discrepancy between the results of the two studies concerns our finding that enemies did not inhibit naming in the withoutonset condition. This is not really surprising, however. Take the example of the enemy prime word-CORD. When the onset is removed (e.g., ord-CORD), the originally irregular pronunciation of the body in word is likely to become regularized. Thus, ord will become a friend for CORD. It is still worth pointing out that the facilitatory effect in this high-frequency irregular condition was smaller than that in all the other conditions (i.e., 8 vs. 13/14 msec).
This may reflect the possibility that bodies of highfrequency irregular words will occasionally keep the irregular pronunciation even if the onset is removed (i.e., ord may be pronounced to rhyme with wORD). Such an interpretation is supported by data from Bowey (1996), which showed that orthographic rimes that are typically irregular in monosyllabic words (e.g., alk, alm) do indeed seem to be given an irregular pronunciation.

Inhibitory body priming is also obtained in the withonset condition at the longest SOA $(100 \mathrm{msec})$, even when primes and targets are friends (hose-NOSE). A similar result has been previously reported by Lukatela and Turvey (1996) with SOAs of less than $250 \mathrm{msec}$. According to Lukatela and Turvey, this early inhibitory effect of the body is due to a process involving competing phonological codes between the prime and the target. Hypothetically, the presentation of the prime activates a phonological representation. With the subsequent presentation of the target, body overlap is thought to reinforce the activation of this previously activated representation, which has not yet fully stabilized. Therefore, the process of resolving the target's phonologicalrepresentation takes place against the background of a strongly competing phonological representation activated by the prime. This competition is thought to slow down the establishment of the target's phonological code.

In conclusion, the present results reconcile seemingly conflicting patterns concerning facilitatory versus inhibitory body priming in naming. It was shown that an inhibitory onset effect typically masks the facilitatory bodypriming effect. When the onset of the prime is removed, robust facilitatory body-priming effects are obtained. Together, these results are consistent with the idea that, even in adult readers, the body is an important psycholinguistic unit in reading.

\section{REFERENCES}

Bowey, J. A. (1990). Orthographic onsets and rimes as functional units of reading. Memory \& Cognition, 18, 419-427.

Bowey, J. A. (1993). Orthographic body priming. Quarterly Journal of Experimental Psychology, 46A, 247-271.

Bowey, J. A. (1996). Phonological recoding of nonword orthographic rime primes. Journal of Experimental Psychology: Learning, Memory, \& Cognition, 22, 117-131.

Bowey, J. A., \& HANSEN, J. (1994). The development of orthographic bodies as units of word recognition. Journal of Experimental Child Psychology, 58, 465-488.

Bowey, J. A., \& UNDERWOOD, N. (1996). Further evidence that orthographic rime usage in nonword reading increases with word-level reading proficiency. Journal of Experimental Child Psychology, 63, 526-562.

Brown, G. D. A. (1987). Resolving inconsistency: A computational model of word naming. Journal of Memory \& Language, 23, 1-23.

Brown, G. D. A., \& WATson, F. L. (1994). Spelling-to-sound effects in single word reading. British Journal of Psychology, 85, 181-202.

Cohen, J., MacWhinney, B., Flatt, M., \& Provost, J. (1993). PsyScope: An interactive graphic system for designing and controlling experiments in the psychology laboratory using Macintosh computers. Behavior Research Methods, Instruments, \& Computers, 25, 257-271.

Forster, K. I., \& DAVIS, C. (1991). The density constraint on formpriming in the naming task: Interference effects from a masked prime. Journal of Memory \& Language, 30, 1-25. 
Forster, K. I., Davis, C., Schoknecht, C., \& CArter, R. (1987). Masked priming with graphemically related forms: Repetition or partial activation? Quarterly Journal of Experimental Psychology, 39A, 211-251.

Forster, K. I., \& TAFT, M. (1994). Bodies, antibodies, and neighborhood density effects in masked form priming. Journal of Experimental Psychology: Learning, Memory, \& Cognition, 20, 844-863.

Grainger, J., \& Ferrand, L. (1996). Masked orthographic and phonological priming in visual word recognition and naming: Cross-task comparisons. Journal of Memory \& Language, 35, 623-647.

Grainger, J., \& JACOBS, A. M. (1999). Temporal integration of information in orthographic priming. Visual Cognition, 6, 461-492.

Jacobs, A. M., Grainger, J., \& Ferrand, L. (1995). The incremental priming technique: A method for determining within-condition priming effects. Perception \& Psychophysics, 57, 1101-1110.

Kinoshita, S. (2000). The left-to-right nature of the masked onset priming effect in naming. Psychonomic Bulletin \& Review, 7, 133-141.

KuČERA,H., \& FrANCIS, W. N. (1967). Computationalanalysis of presentday American English. Providence, RI: Brown University Press.

LukAtela, G., \& Turvey, M. T. (1996). Inhibition of naming by rhyming primes. Perception \& Psychophysics, 58, 823-835.

LuPKer, S. J., \& COLOMBo, L. (1994). Inhibitory effects in form priming: Evaluating a phonological competition explanation. Journal of Experimental Psychology: Human Perception \& Performance, 20, 437-451.

Meyer, A. S. (1990). The time course of phonological encoding in language production: The encoding of successive syllables of a word. Journal of Memory \& Language, 29, 524-545.

MeYER, A. S. (1991). The time course of phonological encoding in language production: Phonological encoding inside a syllable. Journal of Memory \& Language, 30, 69-89.

Peter, M., Lukatela, G., \& Turvey, M. T. (1990). Phonological priming: Failure to replicate in the rapid naming task. Bulletin of the Psychonomic Society, 28, 389-392.

Pexman, P. M., Cristi, C., \& Lupker, S. J. (1999). Facilitation and interference from formally similar word primes in a naming task. Journal of Memory \& Language, 40, 195-229.

Rosson, M. B. (1985). The interaction of pronunciation rules and lexical representations in reading aloud. Memory \& Cognition, 13, 90-99.
TAFT, M. (1992). The body of the BOSS: Subsyllabic units in the lexical processing of polysyllabic words. Journal of Experimental Psychology: Human Perception \& Performance, 18, 1004-1014.

Treiman, R. (1989). The internal structure of the syllable. In G. Carlson \& M. Tanenhaus (Eds.), Linguistic structure in language processing (pp. 27-52). Dordrecht: Kluwer.

Treiman, R, Goswami, U., \& BRUCK, M. (1990). Not all words are alike: Implications for reading development and theory. Memory \& Cognition, 18, 559-567.

Treiman, R., Mullennix, J., Bijeljac-Babic, R., \& RichmondWelty, E. D. (1995). The special role of bodies in the description, use, and acquisition of English orthography. Journal of Experimental Psychology: General, 124, 107-136.

Ziegler, J. C., Ferrand, L., Jacobs, A., Rey, A., \& Grainger, J. (2000). Visual and phonologicalcodes in letter and word recognition: Evidence from incremental priming. Quarterly Journal of Experimental Psychology, 53A, 671-692.

Ziegler, J. C., \& Perry, C. (1998). No more problems in Coltheart's neighborhood: Resolving neighborhood conflicts in the lexical decision task. Cognition, 68, 53-62.

\section{NOTES}

1. Inhibition was obtained at all SOAs except for low-frequency enemies at the shortest SOA.

2. The logic of using a within-condition baseline is straightforward. If overall latencies increase with increasing prime duration, the prime has inhibited target processing. If shorter latencies are obtained in the related condition against an inhibitory unrelated condition, this positive priming effect is due to release from inhibition. If overall latencies decrease with increasing prime duration, the prime has facilitated target processing.

3. We are grateful to Ken Forster for suggesting this interpretation.

(Manuscript received May 27, 1999; revision accepted for publication June 1, 2000.) 